\title{
Tax Planning for Small and Micro Enterprises under the Influence of the 2019-nCoV
}

\author{
Chen Yanbing ${ }^{1}$ \\ ${ }^{1}$ Taxation, School of Finance and Public Administration Yunnan University of Finance and Economics Kunming, Yunnan
}

\begin{abstract}
Due to the sudden outbreak of the 2019-nCoV, many small and micro enterprises are facing great challenges, such as high operating costs, difficulty in returning to work and production, and shortage of cash flow. Starting from the current situation and problems faced by small and micro enterprises under the 2019$\mathrm{nCoV}$, this paper analyzes the tax planning from six basic strategies for the small and micro enterprises, combined with a number of new fiscal and tax policies issued by the government, which not only reduces the tax burden, but also contributes to effective corporate performance management and sustainable development.
\end{abstract}

\section{BASIC CIRCUMSTANCES OF SMALL AND MICRO ENTERPRISES}

In Law of the People's Republic of China on Promotion of Small and Medium-sized Enterprises and Opinions of the State Council on Further Promoting the Development of Small and Medium Enterprises, China classifies the small and medium-sized enterprises as medium-sized enterprises, small-sized enterprises and micro enterprises according to the enterprise of employees, revenue, total assets, and other indicators. The small and micro enterprises in tax should meet the following three conditions: the annual taxable income shall not exceed 3 million yuan, the number of employees shall not exceed 300 , and the total assets shall not exceed 50 million yuan.

In the current market economic system of China, small and micro enterprises are undoubtedly the most active market players, and the proportion is generally on the rise. They are of great value in promoting economic development, alleviating employment pressure, promoting the operation of China's economic structure to be more reasonable, and enhancing the global core competitiveness of China's industrial economy.

Although small and micro enterprises are the most active players in the market, they are also vulnerable. After the sudden outbreak of the 2019-nCoV, the domestic market consumption declined and the demand reduced. According to the data released by the National Bureau of statistics in 2020, the GDP in the first quarter decreased by $6.8 \%$ year-on-year, and the total retail sales of social consumer goods amounted to 78580 billion yuan, representing a year-on-year decrease of $19 \%$. In March, the total retail sales of social consumer goods amounted to 26450 billion yuan, down by $15.8 \%$, and the retail sales of goods decreased by $12 \%$. Most of the small and micro enterprises are confronted with the problems such as insufficient ability to grasp market information, weak ability to control operational risks, and obsolete corporate management concepts, which further aggravate the difficulties of small and micro enterprises.

\section{Problems OF SMALL AND MICRO ENTERPRISES UNDER THE INFLUENCE OF THE 2019-NCOV}

According to the operation index report of small and micro enterprises jointly issued by Economic Daily and Postal Savings Bank of China in February 2020, affected by the epidemic in February, the operation index of small and micro enterprises decreased from 46.1 to 31.9, representing a decrease of 14.2 points.

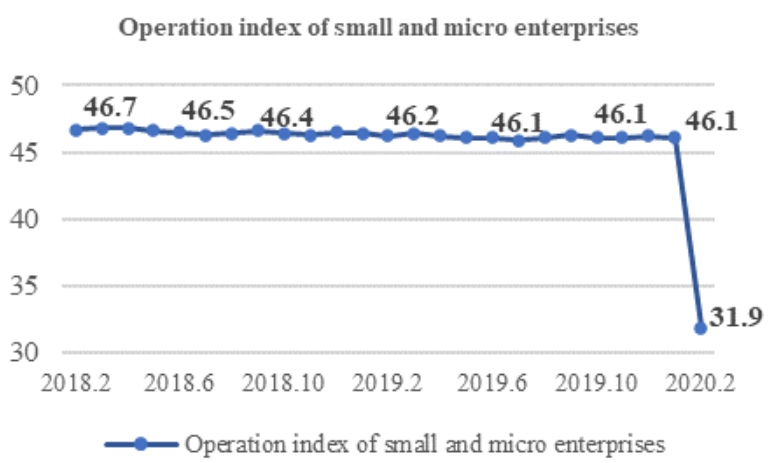

Figure 1 Operation index of small and micro enterprises from February 2018 to February 2020

From the perspective of each sub indicator index, except for the cost index, the other indexes have decreased significantly. It can be seen from Fig. 2 that the performance of small and micro enterprises has declined to varying degrees. 
Operation index of small and micro enterprises

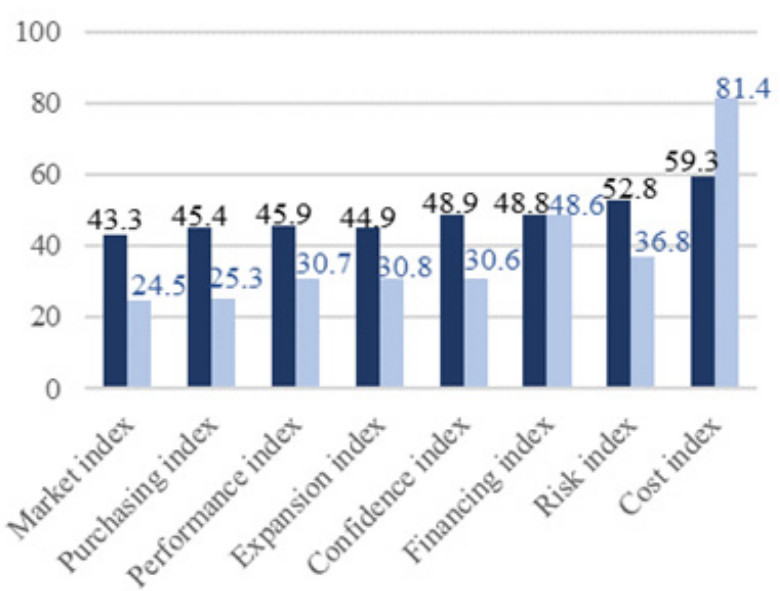

Figure 2 Example of a figure caption. (figure caption)

Most of the small and micro enterprises are confronted with the problems such as insufficient ability to grasp market information, weak ability to control operational risks, and obsolete corporate management concepts, which further aggravate the difficulties of small and micro enterprises.

\subsection{Declining consumer demand and production demand}

Due to the influence of the 2019-nCoV, the consumption demand has been greatly reduced. The enterprises producing means of living, means of production and some related service industries have to limit or suspend production.

\subsection{Poor supply and transportation channels and shortage of materials}

With the sharp decrease in the number of flights and passable roads, transportation has also become a problem faced by enterprises. Blocked supply leads to poor sales, which directly affects the follow-up production of small and micro enterprises, and makes the situation of most enterprises even worse.

\subsection{Heavy burden on production and operation costs}

If the enterprise resumes production, there will be a fixed expenditure which mainly includes water and electricity expenses, store rent and employee wages. Although some enterprises can get the discount of halving store rent, the rest should be paid is still a great burden for small and micro enterprises. It makes enterprise be in a situation of high expenditure and low income. Not only that, the expenditure for preventing the $2019-\mathrm{nCoV}$ is also increased. Because the Enterprises need to take strict measures for epidemic prevention and disinfection. The frequent changes in the prices of anti-epidemic materials also increased the cost of disinfection.

\subsection{A shortage of cash flow}

There is no operating income during the period of business interruption. Even if the enterprise returns to work, the greatly reduced operating income is not enough to fill the exhausted cash flow. The cash is limited, however, the fixed expenses such as employee salary and rent are inevitable. According to the questionnaire survey of 995 small and medium-sized enterprises conducted by Tsinghua University in early February, with the current cash flow, $67.1 \%$ of enterprises can maintain for 2 months, $85.01 \%$ of enterprises maintained for 3 months at most, only $9.96 \%$ of the enterprises can maintain for more than 6 months. The problem of cash flow is serious for small and micro enterprises.

\section{TAX PLANNING AND ANALYSIS FOR SMALL AND MICRO ENTERPRISES UNDER THE INFLUENCE OF THE 2019-NCOV}

Tax planning can effectively lighten the tax burden of small and micro enterprises. Especially during the 2019$\mathrm{nCoV}$, enterprises are faced with the problems of high production and operation costs and cash flow shortage. Tax planning can help enterprises reduce unnecessary expenditures, effectively reduce enterprise costs, and maximize enterprise profits.

According to different enterprises and tax related specific situations, the tax planning methods are flexible and varied. The following will provide thought for small and micro enterprises from six basic strategies of tax planning.

\subsection{Avoiding being objects of taxation}

Avoid being objects of taxation means that the taxpayer reduces or exempts the tax liability by avoiding becoming a tax payer or tax object. Small and micro enterprises can change their products, behaviors or ownership of goods, so as to avoid their products and behaviors belonging to a certain tax category. For example, the scope of the urban land use tax and urban maintenance and construction is the land within cities, counties, designated town and industrial and mining areas. If the taxpayer chooses to build the enterprise outside the above-mentioned areas, it will avoid becoming the tax object of these two taxes.

\subsection{Tax shifting}

There are 3 basic forms of tax shifting: Shifting tax burden forward, shifting tax burden backward and mixed shift of tax burden. When the enterprise increases the sales price by trading activities which is equivalent to putting taxes on the price, and passes it on to the buyer or the consumer, the tax burden is transferred forward. When the tax payment is reversed to the supplier or producer of goods by lowering the purchase price, the tax burden is turned back. Mixed shift of tax burden is the 
process of tax payment transferred to both consumers and suppliers.

If the enterprise has a strong voice in material procurement, it can slightly lower the purchase price of materials. If it has strong competitive advantages in service quality, sales reputation and market share, even a slight price increase will not have a great impact on sales. However, the selection of the specific plan should be judged according to its own business situation, and should avoid the strong reaction of suppliers or consumers.

\subsection{Reducing the tax base}

The tax base directly affects the amount of tax payable, so enterprises should try their best to minimize the tax basis to achieve the purpose of reducing tax. According to the latest policy, the maximum carrying forward period of losses incurred by enterprises in difficult industries affected by the epidemic in 2020 is extended from 5 years to 8 years, including transportation industry, catering industry, accommodation industry, tourism industry (referring to travel agency and related services, scenic spot management) and enterprises with main business income accounting for more than $50 \%$ of total income (excluding non-taxable income and investment income) in 2020. Therefore, in the next 8 years, enterprises can adopt the accrual system to adjust profits, reduce the tax base and minimize the tax burden.

\subsection{Being applicable to a lower tax rate}

If the tax base is determined, the amount of tax payable depends on the tax rate. Many types of taxes have multilevel tax rates and provisions for preferential tax rates. Small and micro enterprises can actively create conditions to apply low tax rates as much as possible. In value-added tax, taxpayers are divided into general taxpayers and small-scale taxpayers. The tax rates of the two types of taxpayers are different. When taxpayers meet certain conditions, they can apply for identity switching, which leaves room for planning. The vat of general taxpayers is levied by difference. When they purchase goods, the input tax they bear can be used for deduction, but the tax rate is relatively high. The vat of small-scale taxpayers is levied on all sales, and no deduction is allowed, but the collection rate is relatively low.

During the 2019-nCoV, the Ministry of Finance and the State Administration of Taxation, issued an announcement to extend the implementation period of the preferential tax policies previously supporting the resumption of work of individual business and small and micro enterprises to 31 December 2020. According to the previous announcements issued by the 2 departments, from 1 March 2020 to 31 May, for small-scale VAT taxpayers in Hubei Province, the VAT on taxable sales income which is at a tax rate of $3 \%$ is exempted, and on the prepaid VAT project with a rate of $3 \%$ is suspended. Except for Hubei Province, for small-scale VAT taxpayers in other provinces, VAT on the taxable sales income subject which is at the rate of $3 \%$ shall be levied at a reduced rate of $1 \%$, and VAT on the prepayment subject at the rate of $3 \%$ shall be reduced to the rate of $1 \%$.

\subsection{Delaying tax payment}

An enterprise can delay the tax payment by delaying the realization of sales revenue, installment sales and longterm project revenue, or changing the depreciation method and depreciation period of fixed assets, shortening the amortization period of intangible assets and deferred assets, or reasonably arranging the prepayment method of income tax.

The delay of the tax payment period is equivalent to that the enterprise receives a government interest free loan equivalent to the tax payment during the period of delay. For example, enterprises engaging in import business, their tax payment obligations are closely related to the time of customs declaration. The occurrence time of tax obligation can be delayed by flexible use of customs declaration time. The later the tax is paid, the more objective time gains can be obtained. Sometimes the problem of liquidity turnover encountered by enterprises can be solved.

In particular, during the 2019-nCoV, according to the announcement of the State Administration of Taxation, from 1 May 2020 to 31 December, small and micro profit enterprises may suspend the payment of current enterprise income tax, after handling the prepayment declaration in the remaining reporting period of 2020 according to regulations. It can be deferred to the first reporting period in 2021. If Small and micro enterprises, which filing the second and third quarter enterprise income tax prepayment declaration in July and October 2020, only declare and do not pay the corporate income tax, the tax payable will be postponed to January 2021 and paid together with the tax in the fourth quarter of 2020. Enterprises shall carefully check the relevant documents, postpone tax declaration and hold cash to the maximum extent according to their own conditions.

\subsection{Making full use of preferential tax policies}

\subsubsection{Reducing costs}

\subsubsection{Rent reduction.}

For small and micro enterprises in the service industry and individual business that have difficulties in leasing state-owned houses for operation, the house rental for at least 3 months in the first half of the year shall be exempted. In the first half of the year, the period of exemption is insufficient, and it will be complemented or postponed in the second half of the year according to the requirements of the location of the housing. The specific implementation plan varies in different regions. For 
example, in Beijing, only when the small and micro enterprises insist on operating as required by the government, or close down in accordance with epidemic prevention regulations without laying off staff or reducing the number of employees, can the rent be reduced or reduced.

\subsubsection{The cost of water, gas and electricity reduction.}

In the second half of 2020, when the power grid enterprises charge the electricity fees of the power users (including the users who have participated in the market transactions) except for the high energy consumption industries, who currently implement the general industrial and commercial tariffs and other tariffs, and the large industrial tariffs, they will continue to settle the electricity fees at $95 \%$ of the original household price level. The cost of water and gas consumption of enterprises has also been reduced, and specific policies vary from province to province.

\subsubsection{Reducing taxes and fees and increasing bonus and compensation.}

\subsubsection{Value added tax(VAT).}

If the annual taxable income of small and micro profit enterprises does not exceed 1 million yuan, $25 \%$ shall be included in the taxable income and the enterprise income tax shall be paid at the rate of $20 \%$. If the annual taxable income exceeds 1 million yuan but does not exceed 3 million yuan, $50 \%$ shall be included in the taxable income and the enterprise income tax shall be paid at the rate of $20 \%$.

\subsubsection{Enterprise income tax.}

If the annual taxable income of small and micro profit enterprises does not exceed 1 million yuan, $25 \%$ shall be included in the taxable income and the enterprise income tax shall be paid at the rate of $20 \%$. If the annual taxable income exceeds 1 million yuan but does not exceed 3 million yuan, $50 \%$ shall be included in the taxable income and the enterprise income tax shall be paid at the rate of $20 \%$.

\subsubsection{Other taxes.}

For small-scale VAT taxpayers, resource tax, urban maintenance and construction tax, property tax, urban land use tax, stamp tax, arable land occupation tax, education supplementary tax and local education supplementary tax shall be reduced by $50 \%$ of the tax amount. Small scale VAT taxpayers, who have already enjoyed other preferential policies such as resource tax, urban maintenance and construction tax, property tax and so on according to law, can also enjoy the preferential policies of $50 \%$ reduction. What's more, financial institutions and small and micro enterprises are exempted from stamp duty when signing loan contracts.

\subsubsection{Government funds.}

- Taxpayers with monthly sales of no more than 100 thousand yuan (quarterly sales subject to quarterly tax of no more than 300 thousand yuan) are exempted from education surcharges, local education surcharges and water conservancy construction funds.

- The taxpayers who fail to reach the VAT threshold shall be exempted from the construction fee of cultural undertakings.

- For small and micro enterprises with a total number of employees of less than 30 (including), the residual insurance fund is temporarily exempted.

\subsubsection{Financial rewards and subsidies}

- Provide key prevention and control materials production enterprises with employment subsidies.

- Give subsidies to key production enterprises of prevention and control materials for increasing production and capacity through technological transformation, and small and medium-sized enterprises to purchase more equipment.

- Give subsidies to key production enterprises of prevention and control materials for increasing production and capacity through technological transformation, and small and medium-sized enterprises to purchase more equipment.

- Give subsidies and rewards to stable work or new recruits during 2019-nCoV.

- For small and micro enterprises that temporarily lose their income sources, priority will be given to support them in applying for loans.

\section{ConClusion}

To sum up, the ability of small and micro enterprises in risk response, crisis resolution and policy interpretation, has been fully tested during 2019-nCoV. Small and micro enterprises should make full use of relevant new policies on finance and taxation to turn crisis into opportunities, seize opportunities and seek development.

On the one hand, from the perspective of increasing income, small and micro enterprises can integrate resources, research products or services that can be provided during the epidemic, give full play to their own advantages and respond flexibly. For example, using the existing sterile workshop to produce masks, the state has provided a variety of preferential policies for the enterprises which produce materials for epidemic prevention and control.

On the other hand, from the perspective of increasing sources of funds, there are many ways for enterprises to obtain the support of national fiscal and taxation policies and financial policies. In addition, it is also one of the ways to increase capital by issuing bonds in capital market and bond market. 
There is no doubt that tax planning is of great importance to the long-term development of small and micro enterprises. Under the influence of the 2019$\mathrm{nCoV}$, small and micro enterprises need to face up to their own shortcomings in tax planning and speed up the construction of enterprise tax planning. It is also important to establish a correct concept of tax planning and standardize the financial management system of enterprises. In order to further promote the sustainable development of small and micro enterprises, enterprises should establish more scientific and reasonable tax planning objectives and reduce unnecessary expenses as much as possible.

\section{REFERENCES}

1. Meng Fanhong. Analysis on the dilemma of small and medium-sized enterprises under the impact of new crown pneumonia [J]. Heilongjiang Finance, May 2020: 45-47.
2. Paul Liu. Research on tax planning of small and micro enterprises [D]. Chongqing University of Technology, 2018.

3. Guo Jingzhao, Liu Zhengxia. Corporate tax planning strategy under the influence of new coronavirus (2019-nCoV) [J]. Value Engineering, 2020,39 (18): 6-8.

4. Yang Yanjun. Interpretation of preferential tax policies for small and micro enterprises and suggestions for tax planning [J]. Taxation, 2020, 14 (18): $50+52$.

5. Research group of small and micro enterprises operation index of Economic Daily - Postal Savings Bank of China. Affected by the epidemic, the performance of small and micro enterprises decreased to varying degrees [n]. Economic Daily, 2020-03-06 (012) 